\title{
Clinical application of serum anti-Müllerian hormone in women
}

\author{
So Ra Oh, Sun Yi Choe, Yeon Jean Cho \\ Department of Obstetrics and Gynecology, Dong-A University Medical Center, Dong-A University College of Medicine, Busan, Korea
}

Anti-Müllerian hormone (AMH), a peptide growth factor of the transforming growth factor- $\beta$ family, is a reliable marker of ovarian reserve. Regarding assisted reproductive technology, AMH has been efficiently used as a marker to predict ovarian response to stimulation. The clinical use of AMH has recently been extended and emphasized. The uses of AMH as a predictive marker of menopause onset, diagnostic tool for polycystic ovary syndrome, and assessment of ovarian function before and after gynecologic surgeries or gonadotoxic agents such as chemotherapy have been investigated. Serum AMH levels can also be affected by environmental and genetic factors; thus, the effects of factors that may alter AMH test results should be considered. This review summarizes the findings of recent studies focusing on the clinical application of AMH and factors that influence the AMH level and opinions on the use of the AMH level to assess the probability of conception before reproductive life planning as a"fertility test."

Keywords: Anti-Müllerian hormone; Fertility; Ovarian reserve; Polycystic ovary syndrome; Surgery

\section{Introduction}

Anti-Müllerian hormone (AMH), a peptide growth factor of the transforming growth factor- $\beta$ family [1], is well known for its role in sexual differentiation. In men, AMH is secreted from the Sertoli cells of the testes, promotes Müllerian duct regression, and initiates male phenotypic development. Without AMH, the Müllerian ducts differentiate into the uterus, one-third of the vagina, and oviducts [2,3].

When primordial follicles are recruited, AMH is initially produced in granulosa cells [4]. AMH expression continues to increase until primordial follicles have developed into small antral follicles approximately 4-6 mm in size [5]. In a study of AMH-knockout (AMHKO)

Received: Mar 29, 2019 · Revised: May 20, 2019 · Accepted: May 22, 2019 Corresponding author:Yeon Jean Cho

Department of Obstetrics and Gynecology, Dong-A University Medical Center, Dong-A University College of Medicine, 26 Daesingongwon-ro, Seo-gu, Busan 49201, Korea

Tel: +82-51-240-5090 Fax:+82-51-244-9553 E-mail:jeanjane@dau.ac.kr

* This work was supported by the Dong-A University research fund.

This is an Open Access article distributed under the terms of the Creative Commons Attribution Non-Commercial License (http://creativecommons.org/licenses/by-nc/4.0/) which permits unrestricted non-commercial use, distribution, and reproduction in any medium, provided the original work is properly cited. mice, female AMHKO mice showed faster recruitment of primordial follicles and earlier depletion of follicles than wild-type female mice, suggesting that $\mathrm{AMH}$ inhibits the initiation of primordial follicular growth and prevents premature follicular exhaustion $[4,6,7]$. Further, Nilsson et al. [8] found that AMH had an inhibitory effect on factors such as stem cell factor (kit ligand) and basic fibroblast growth factor, which are known to stimulate primordial follicular recruitment. When follicles have reached $8 \mathrm{~mm}$, AMH levels rapidly decrease, becoming undetectable during follicle stimulating hormone (FSH)-dependent stages or in follicles showing signs of atresia [6,9]. Antral follicles producing less $\mathrm{AMH}$ are more sensitive to $\mathrm{FSH}$, which allows continued growth and ovulation [10]. AMH may down-regulate the aromatizing capacity of granulosa cells, which reduces estradiol $\left(E_{2}\right)$ production until final follicular selection [11-13]. When follicles have grown sufficiently, AMH levels rapidly decrease, while $E_{2}$ production increases rapidly thereafter [14]. This transition of the $E_{2}$ level correlates with dominant follicular selection. $E_{2}$ has opposite action through estrogen receptor (ER) $\beta$ and ERa on AMH expression. Because dominant follicles have more $E R \beta$ than $E R a, E_{2}$ inhibits $A M H$ transcription via ERß [14].

As many women of reproductive age delay childbearing, interest in 
ovarian function and fertility is increasing. Regarding assisted reproductive technology (ART), AMH has been used efficiently to predict ovarian response to stimulation. The clinical use of $\mathrm{AMH}$ was recently extended and emphasized. In this review, we discuss AMH in relation to ovarian function, fertility, and various factors and conditions to consider before its clinical application and interpretation.

\section{Serum AMH level and its role as an ovarian reserve marker in women}

In women, $\mathrm{AMH}$ is produced and secreted from ovarian granulosa cells from approximately 36 weeks of gestation to menopause $[15,16]$. AMH level is very low and barely detectable in the neonatal period; however, a modest increase occurs a few weeks after birth, and the level peaks at around 25 years of age [2]. As the pool of small growing follicles is in parallel with the total number of primordial follicles, AMH reflects ovarian reserve [17]. During the early follicular phase, the antral follicle count (AFC) and AMH levels are correlated [18]. Unlike other biomarkers for ovarian reserve, such as FSH and inhibin $B, A M H$ levels fluctuate minorly during normal menstrual cycles. Tsepelidis et al. [19] explained that AMH secretion is mostly affected by the early follicular recruitment rate of the follicular pool, which is independent of the menstrual cycle. This Serum AMH level stability regardless of the menstrual cycle makes it much easier to use it to evaluate ovarian reserve than other markers. Although the individual variability of AMH is low, differences in the degree of fluctuations with age have been observed [20,21]. Studies showed an inverse correlation with age and AMH fluctuation degree, which indicated that younger patients with usually high ovarian reserves had greater fluctuations in AMH levels.

As the ovarian follicular pool decreases with age, markers for ovarian reserve also change. The FSH level increases after 35 years of age [22], while the inhibin B level decreases with age [23-25]. Until 40 years of age, neither FSH nor inhibin B shows a definite correlation with age. These endocrine changes seem to occur when the number of follicles significantly decreases [26]. In Korea, Lee et al. [27] described an age-specific model of AMH that may be helpful for evaluating the ovarian reserve of infertile women. However, an absolute age-specific AMH level to evaluate ovarian reserve at that time is somewhat limited. A nomogram of patients of other ethnicities ranging from infancy to adulthood has been reported $[28,29]$. Briefly, AMH showed a longitudinal decline over time after peaking in the mid-twenties, suggesting that AMH reflects the decline in the ovarian follicular pool with age better than any other ovarian reserve markers [26,27].

\section{Clinical application of AMH}

\section{Use as a prediction marker of ovarian response in controlled ovarian stimulation}

Serum AMH levels have been used to predict the quantitative and qualitative aspects of controlled ovarian stimulation (COS). About one-third of women who undergo in vitro fertilization yield a larger number of oocytes than expected $[11,30,31]$. These excessive responses may lead to a lower probability of pregnancy, poorer-quality embryos, or even cycle cancellation [32-38]. In an individual patient data meta-analysis of 4,786 women, the prognostic power for predicting an excessive ovarian response using serum AMH level, AFC, and age have been suggested [39]. According to their model, serum AMH level, AFC, and patient age showed an area under the receiver operating characteristic curve (AUC) of 0.85 . Even without age, the use of AMH level and AFC for predicting excessive response in $\operatorname{COS}$ had similar accuracies. These findings indicate that serum AMH level and AFC may present good predictive accuracy for excessive response with adding value to female age.

High basal AMH levels may also increase a patient's risk of developing ovarian hyperstimulation syndrome (OHSS). Four prospective studies that included large numbers of subjects reported relevant values of AMH for predicting hyper-response and OHSS [40-43]. One study showed that the cutoff value of $3.36 \mathrm{ng} / \mathrm{mL}$ measured by Diagnostic System Laboratories predicted OHSS with $90.5 \%$ sensitivity and $81.3 \%$ specificity [42].

In addition, AMH is used to predict poor responders in COS; however, there is no clear standard definition of a poor responder [44]. Several authors studied the usefulness of AMH for predicting a poor response to gonadotropin. For example, Lee et al. [45] investigated the cutoff level of serum AMH for predicting poor (number of oocytes retrieved, $\leq 3$ ), normal (4-19), and high responders ( $\geq 20$ ). Especially for predicting poor responders, the cutoff level was $1.08 \mathrm{ng} / \mathrm{mL}$, with $85.8 \%$ sensitivity and $78.6 \%$ sensitivity. These results can be used to determine the recombinant human FSH starting dose and predict the final oocyte yields and develop a nomogram that could predict oocyte yield. Moon et al. [46] developed nomograms that could predict oocyte yield using age, basal serum FSH level, serum AMH level, and AFC in a Korean population. Briefly, AMH measurement helps predict the extremes of ovarian response to gonadotropin stimulation. Many studies have unsuccessfully attempted to obtain results of the prediction value of AMH for qualitative aspects of ART, such as oocyte quality, embryo quality, and implantation and pregnancy rates [47].

\section{Use as a marker for predicting age at menopause}

Predicting age at menopause may help women prepare their post- 
menopausal life as well as their late reproductive life, especially for women concerning early menopause. However, no marker can currently be used to predict the exact age of menopause. Since $\mathrm{AMH}$ reflects the gradual decline in reproductive capacity with age, it is receiving increasing attention as a potential marker for menopause [26,48-50].

Broer et al. [51] presented a model that related an age-specific AMH level percentile with the predicted age at menopause. For example, a 30-year-old woman with an AMH level close to $0.15 \mathrm{ng} / \mathrm{mL}$ was categorized under the fifth percentile $(p)$; therefore, predicted mean age at menopause was 48.8 years ( $p 5$ to $p 95,42.1-53.0$ years). They suggested that menopause timing could be individually calculated. However, as the range of the predicted menopausal age is too wide to accurately predict the exact age, its application in clinical practice may be limited.

Whether AMH could become a clinically valuable indicator of the risk of early menopause has not been assessed. Several populationbased studies conducted to date have included sufficient numbers of women undergoing early natural menopause to evaluate this relationship. A recent prospective study of 327 women with early menopause showed that the mean AMH level was significantly lower in cases $(0.40 \mathrm{ng} / \mathrm{mL})$ than in controls $(1.9 \mathrm{ng} / \mathrm{mL} ; p<0.001)$ [52]. Every AMH level decrease of around $0.10 \mathrm{ng} / \mathrm{mL}$ was related with a $14 \%$ increased risk of early menopause $(p<0.001)$. Furthermore, a metaanalysis of 2,596 female patients (of whom 1,077 were menopausal) showed that the combination of AMH and age was more reliable in the prediction of early menopause than age alone [53]. Despite all the studies, more accurate threshold for AMH level needs to be defined, and other variables, such as family history of early menopause, maternal age at menopause, and lifestyle factors (smoking, body mass index [BMI], use of alcohol, and parity) should also be considered.

\section{Factors that affect serum AMH levels}

$\mathrm{AMH}$ is a test that represents ovarian reserve but is not dependent on the menstrual cycle. Nonetheless, it can be affected by environmental and genetic factors [54-57]. These factors may lead to errors in the interpretation of serum AMH levels in clinical practices. One important element in the clinical setting is awareness of the factors that affect serum AMH levels. Here we describe the most common issues associated with AMH level variations in women.

\section{1) Polycystic ovary syndrome}

Polycystic ovary syndrome (PCOS) is one of the most common ovulatory disorders. The serum AMH level is two- to three-fold higher among women with PCOS than among normo-ovulatory women, in line with the increased number of small antral follicles in PCOS
$[58,59]$. AMH production is highly increased (by up to 75 -fold) in granulosa cells of anovulatory polycystic ovaries compared to that in granulosa cells in normal controls [60]. Dewailly et al. [61] noted that the number of small follicles ( $2-5 \mathrm{~mm}$ in size) was positively correlated with the severity of menstrual disturbances in PCOS, especially in women with amenorrhea. Using a threshold AMH level of $11.4 \mathrm{ng} / \mathrm{mL}$, serum AMH could predict amenorrhea with $91.7 \%$ specificity and 79.4\% sensitivity in PCOS [62]. Taken together, these findings imply that anovulatory patients with PCOS have an increased number of small antral follicles producing $\mathrm{AMH}$, leading to an $\mathrm{AMH}$-dominant microenvironment, which interferes with the actions of FSH on follicles, leading to anovulation and amenorrhea.

Factors related to the pathophysiology of PCOS, such as increased luteinizing hormone (LH) levels, increased androgen levels, and insulin resistance may be associated with elevated serum AMH levels. $\mathrm{LH}$ is known to increase AMH production up to four-fold in granulosa cells of PCOS ovaries and elevates AMH expression in the granulosa cells of oligo- or anovulatory PCOS women [60,63], implying a role of $\mathrm{LH}$ in excessive AMH expression and follicular arrest. Androgens stimulate the FSH-independent stages of follicular development $[64,65]$ and may increase $\mathrm{AMH}$ production. A positive correlation was noted between fasting insulin and AMH levels in PCOS and nonPCOS women [66]. In contrast, an independent inverse relationship was identified between insulin resistance and $\mathrm{AMH}$ in women without PCOS, probably by an abnormal effect of insulin action on $\mathrm{AMH}$ secretion from granulosa cells [67]. The exact relationship between insulin resistance and $\mathrm{AMH}$ has not been fully elucidated.

\section{2) History of ovarian surgery}

Several histologic analyses have shown that normal ovarian tissues can be unintentionally removed in most cases of ovarian cystectomy, especially for ovarian endometrioma [68-71]. Electrocoagulation may also damage the ovarian blood supply and stroma [68,72]. Postoperative damage to the ovarian reserve can be assessed by comparing pre- and postoperative AMH levels [73]. Chang et al. [74] prospectively evaluated a series of declining changes in serum $\mathrm{AMH}$ levels after laparoscopic ovarian cystectomy. The median AMH level at 3 months postoperative was about $65 \%$ that of the preoperative level ( $2.23 \mathrm{ng} / \mathrm{mL}$ before surgery vs. $1.50 \mathrm{ng} / \mathrm{mL}$ at 3 months postoperative).

It is unclear whether the postoperative decline in AMH is comparable between endometrioma and other benign ovarian cysts. A recent study reported that women with endometriomas had considerably lower baseline AMH levels than women without endometriosis [75]. The presence of an endometrioma may contribute to a decline in ovarian reserve [76]. Therefore, patients with already diminished ovarian reserve should be warned before surgery about the possibili- 
ty of premature ovarian insufficiency after surgical intervention and the need for fertility preservation. Clinicians should consider that the $\mathrm{AMH}$ level could be low in women with a history ovarian surgery. Ovarian cyst bilaterality is the most significant factor in predicting AMH level decreases after laparoscopic surgery $(p<0.001)$ [77]. Thus, patients with low preoperative AMH levels should be managed more carefully.

\section{3) Chemotherapy}

Since chemotherapy is detrimental to female fertility, researchers have attempted to predict the risks of decreased ovarian reserve in women with planned chemotherapy. A prospective study of women treated with chemotherapy for early breast cancer showed that longterm ovarian function after treatment was predictable using serum $\mathrm{AMH}$ levels before treatment. This predictive value of serum $\mathrm{AMH}$ level was superior to age as well as inhibin B and FSH levels [78]. The primary cutoff values of the pre-chemotherapy $\mathrm{AMH}$ level were $<0.53 \mathrm{ng} / \mathrm{mL}$ for predicting amenorrhea and $>2.84 \mathrm{ng} / \mathrm{mL}$ for predicting ongoing menses.

The role as a predictive marker for ovarian function recovery after ovarian protection by gonadotropin-releasing hormone ( $\mathrm{GnRH}$ ) agonists during chemotherapy in young breast cancer patients was emphasized [79]. If the pretreatment AMH level is $>3.26 \mathrm{ng} / \mathrm{mL}$, the AMH level 1 year after GnRH agonist therapy is expected to be at least $1 \mathrm{ng} / \mathrm{mL}$ regardless of age or pretreatment FSH level. Meanwhile, Kim et al. [80] determined that the post-chemotherapy $\mathrm{AMH}$ level is an independent predictor of ovarian function recovery among breast cancer patients with amenorrhea after chemotherapy. An AMH level $\geq 0.8 \mathrm{ng} / \mathrm{mL}$ may reflect the recovery of menstruation for 5 years. Studies of the role of the prechemotherapy AMH level in predicting the restoration of menstruation and fertility after treatment will continue since fertility preservation is very important in these patients.

\section{4) Oral contraception}

Ovarian reserve parameters are lower among users than non-users of combined oral contraceptives (COC) [81-83]. A cross-sectional study of a total of 887 women aged 19-46 years using COC showed decreased overall ovarian reserve parameters, i.e., ovarian volume, AFC, and AMH level significantly decreased by $50 \%$ ( $95 \%$ confidence interval [Cl], 45.1\%-53.7\%), 18\% (95\% Cl, 11.2\%-24.8\%), and 19\% (95\% Cl, 9.1\%-29.3\%), respectively [84]. They found a considerable decrease in the number of small antral follicles with age and detected a similar shift toward smaller AFC subclasses in women using COC. The diminished overall number of antral follicles and suppressed FSH could explain the decreased AMH levels in COC users versus non-users. For this reason, clinicians should be cautious when assessing ovarian reserve in COC users. The actual AMH level and AFC are probably $20 \%$ higher than the measured values in COC users. The suppressive effect of $\mathrm{COC}$ is known to recover within 3-6 months $[81,85]$. When counseling COC users about their reproductive lifespan and fertility status, AMH level or AFC alone should not be used, but it could be used as a sub-reference value.

\section{5) Obesity}

Obesity is well known for its negative effects on reproduction, including ovulatory dysfunction, infertility, miscarriage, and other reproductive complications [86]. A cross-sectional study of AMH levels in relation with $\mathrm{BMI}$ at a late reproductive age (range, 35-47 years) revealed that women with a BMI $\geq 30 \mathrm{~kg} / \mathrm{m}^{2}$ had $65 \%$ lower AMH levels than women with a BMl $<30 \mathrm{~kg} / \mathrm{m}^{2}(0.016 \mathrm{ng} / \mathrm{mL}$ vs. $0.046 \mathrm{ng} / \mathrm{mL})$ [87]. For infertile women with diminished ovarian reserve (baseline serum FSH $>10 \mathrm{IU} / \mathrm{L})$, women with a higher BMI ( $\left.\geq 25 \mathrm{~kg} / \mathrm{m}^{2}\right)$ women had 33\% lower serum AMH levels than normal BMI women [88]. A recent meta-analysis including 26 studies showed $B M I$ is negatively correlated with AMH in the overall population [89].

Because of the altered hormonal metabolism in obese women, an inverse association of $\mathrm{BMI}$ and $\mathrm{AMH}$ has been described. However, the mechanism of obesity influencing AMH levels has not been fully elucidated [87].

\section{6) $B R C A$ mutations}

Mutations of the $B R C A 1$ and $B R C A 2$ genes are known to contribute to the increased susceptibility to breast and ovarian cancers. The expression of $B R C A 1$ and $B R C A 2$ during human embryo development is known to affect embryogenesis, ovarian function, and female fertility [90]. Oktay et al. [91] reported that breast cancer patients with the $B R C A 1$ mutation had significantly poorer response to ovarian stimulation ( $\leq 4$ retrieved oocytes) than non-carriers. These findings indicated that BRCA mutations can cause excess DNA damage in oocytes that would result in a smaller oocyte reserve and premature ovarian failure. Various studies have also reported on the association between $B R C A$ mutation status and serum AMH values. A cross-sectional study of women with a family history of breast cancer showed significantly low AMH levels in BRCA1 mutation carriers but not in BRCA2 mutation carriers [92]. In contrast, Johnson et al. [93] reported that carriers of the BRCA2 mutation had more decreased AMH levels than noncarriers. Meanwhile, Michaelson-Cohen et al. [94] showed no significant differences in AMH levels between BRCA1/2 mutation carriers and the general population. Given these various study results, more research is needed.

\section{7) Vitamin D deficiency}

Vitamin $D$ is a steroid hormone that acts through the nuclear gene 
transcription factor, and interest has increased in the role that vitamin D plays in female reproductive health. Merhi et al. [95] observed that women with insufficient and deficient levels of 25-hydroxyvitamin D (250H-D) in follicular fluids ( $<30 \mathrm{ng} / \mathrm{mL}$ ) showed a two-fold increase in AMHRII messenger RNA (mRNA) expression levels compared to those with sufficient ( $\geq 30 \mathrm{ng} / \mathrm{mL}$ ) $25 \mathrm{OH}$-D levels. Vitamin D supplementation can counteract the repressive effect of AMH on granulosa cells and lead to follicular maturation. In a study of premenopausal women, 250H-D and AMH levels exhibited seasonal variations in women with an $18 \%$ decrease in AMH levels in winter versus summer. They suggested that vitamin $D$ supplementation prevented seasonal AMH changes [96]. In contrast, Pearce et al. [97] showed no correlation between serum AMH and vitamin D levels in PCOS or ovulatory women. Similarly, Drakopoulos et al. [98] reported that serum vitamin $D$ levels had no association with ovarian reserve markers (AMH level, total AFC). Conflicting results from various clinical studies suggest the necessity for further research to reveal the actual effect of vitamin D on AMH levels.

\section{Serum AMH level and PCOS diagnosis}

As serum AMH level reflects excess small follicles not visible on ultrasonography, AMH level would theoretically be more accurate than the AFC $[83,99,100]$, lending support to the notion that AMH may play a role in the diagnosis of PCOS. Given the strong implication of AMH in PCOS, AMH level could be used as a biomarker of the diagnosis of PCOS. Dewailly et al. [100] showed that a cutoff at $4.9 \mathrm{ng} / \mathrm{mL}$ had a high specificity of $97 \%$ and a better sensitivity of $92 \%$ than the AFC to distinguish patients with PCOS from normal women. A recent meta-analysis indicated that the cutoff value of $4.7 \mathrm{ng} / \mathrm{mL}$ had a sensitivity of $82.8 \%$ and a specificity of $79.4 \%$ for PCOS diagnosis, with an AUC of 0.87 [101]. However, there is currently no universal and consensual diagnostic threshold for serum AMH in the disagnosis of PCOS. The new European Society of Human Reproduction and Embryology guidelines, published in 2018, do not recommend the use of serum AMH levels as an alternative for detecting polycystic ovarian morphology (PCOM) or as a single test result for the diagnosis of PCOS [102].

In the future, with improved standardization of assays and established cut-off values based on large-scale validation in populations of different ethnicities and ages, AMH may be used as a precise diagnostic tool for PCOS or PCOM [101-103].

\section{Opinions on the use of AMH level as a "fertility test"}

Because of the convenience of sampling regardless of menstrual cycle and known age-specific values, AMH is now preferred as a biomarker to evaluate ovarian reserve in women. Serum AMH measurement is being considered a screening tool for women who want to preserve their fertility in some clinical situations. However, the usefulness of AMH as a "fertility test" is not well known. Recently, Steiner et al. [104] determined the extent to which biomarkers of ovarian reserve are associated with reproductive potential among late reproductive-age women (age, 33-44 years). They concluded that women with low AMH levels $(<0.7 \mathrm{ng} / \mathrm{mL})$ did not have a significant difference in predicted probability of conception by 12 attempted cycles compared to women with normal AMH levels. They also found that, among women without a history of infertility who attempted to conceive for less than 3 months, biomarkers that reflected diminished ovarian reserve were not associated with decreased fertility. On the other hand, Koo et al. [105] evaluated the association between serum $\mathrm{AMH}$ level and pregnancy rate and time to pregnancy after timed intercourse in 202 infertile women younger than 35 . The pregnancy rate after timed intercourse was not significantly different between normal AMH and low AMH groups $(<2.5 \mathrm{ng} / \mathrm{mL}$ for women $\leq 31$ years and $<2.0 \mathrm{ng} / \mathrm{mL}$ for women $32-34$ years). However, the time to pregnancy was longer in the very low AMH group $(<1.19$ $\mathrm{ng} / \mathrm{mL}$ for women $\leq 31$ years and $<0.6 \mathrm{ng} / \mathrm{mL}$ for women $32-34$ years) than in the normal AMH group with statistical significance.

These inconsistent findings imply that using AMH levels to assess natural fertility for women without a history of infertility or subfertility may be inappropriate, even in late reproductive-age women. There is consensus of $\mathrm{AMH}$ as a good marker of ovarian reserve, but there is no current agreement on its use as a fertility screening test in fertile women.

\section{Conclusion}

Measuring serum AMH to predict an ovarian response to stimulation in ART, menopausal onset, and iatrogenic amenorrhea may be useful; thus, it must be added to individualized patient counseling. Given the strong implication of $\mathrm{AMH}$ in the pathophysiology of PCOS, AMH may be a biomarker of PCOS diagnosis in the future. It could be considered a screening parameter in selected populations of women for assisting with their reproductive life planning. However, agreement on its use as a screening tool in fertile populations is lacking. In the future, an international consensus on the screening of ovarian reserve in general populations of reproductive-age women is expected.

\section{Conflict of interest}

No potential conflict of interest relevant to this article was reported. 


\section{ORCID}

$\begin{array}{ll}\text { So Ra Oh } & \text { https://orcid.org/0000-0001-8085-7861 } \\ \text { Sun Yi Choe } & \text { https://orcid.org/0000-0002-6890-1329 } \\ \text { Yeon Jean Cho } & \text { https://orcid.org/0000-0003-2755-4970 }\end{array}$

\section{Author contributions}

Conceptualization, Data curation, Formal analysis, Funding acquisition, Methodology, \& Project administration: YJC. Visualization: SRO. Writing - original draft: SRO. Writing - review \& editing: SYC.

\section{References}

1. Cate RL, Mattaliano RJ, Hession C, Tizard R, Farber NM, Cheung A, et al. Isolation of the bovine and human genes for Mullerian inhibiting substance and expression of the human gene in animal cells. Cell 1986;45:685-98.

2. Lee MM, Donahoe PK. Mullerian inhibiting substance: a gonadal hormone with multiple functions. Endocr Rev 1993;14:152-64.

3. Josso N, Cate RL, Picard JY, Vigier B, di Clemente N, Wilson C, et al. Anti-mullerian hormone: the Jost factor. Recent Prog Horm Res 1993;48:1-59.

4. Durlinger AL, Gruijters MJ, Kramer P, Karels B, Ingraham HA, Nachtigal MW, et al. Anti-Mullerian hormone inhibits initiation of primordial follicle growth in the mouse ovary. Endocrinology 2002;143:1076-84.

5. Weenen C, Laven JS, Von Bergh AR, Cranfield M, Groome NP, Visser JA, et al. Anti-Mullerian hormone expression pattern in the human ovary: potential implications for initial and cyclic follicle recruitment. Mol Hum Reprod 2004;10:77-83.

6. Durlinger AL, Visser JA, Themmen AP. Regulation of ovarian function: the role of anti-Mullerian hormone. Reproduction 2002;124:601-9.

7. Durlinger AL, Kramer P, Karels B, de Jong FH, Uilenbroek JT, Grootegoed JA, et al. Control of primordial follicle recruitment by anti-Mullerian hormone in the mouse ovary. Endocrinology 1999;140:5789-96.

8. Nilsson E, Rogers N, Skinner MK. Actions of anti-Mullerian hormone on the ovarian transcriptome to inhibit primordial to primary follicle transition. Reproduction 2007;134:209-21.

9. Andersen CY, Schmidt KT, Kristensen SG, Rosendahl M, Byskov $A G$, Ernst E. Concentrations of AMH and inhibin-B in relation to follicular diameter in normal human small antral follicles. Hum Reprod 2010;25:1282-7.

10. Baarends WM, Uilenbroek JT, Kramer P, Hoogerbrugge JW, van Leeuwen EC, Themmen AP, et al. Anti-mullerian hormone and anti-mullerian hormone type II receptor messenger ribonucleic acid expression in rat ovaries during postnatal development, the estrous cycle, and gonadotropin-induced follicle growth. Endocrinology 1995;136:4951-62.

11. Andersen CY, Byskov AG. Estradiol and regulation of anti-Mullerian hormone, inhibin- $A$, and inhibin-B secretion: analysis of small antral and preovulatory human follicles' fluid. J Clin Endocrinol Metab 2006;91:4064-9.

12. Andersen CY, LossI K. Increased intrafollicular androgen levels affect human granulosa cell secretion of anti-Mullerian hormone and inhibin-B. Fertil Steril 2008;89:1760-5.

13. Grossman MP, Nakajima ST, Fallat ME, Siow Y. Mullerian-inhibiting substance inhibits cytochrome P450 aromatase activity in human granulosa lutein cell culture. Fertil Steril 2008;89(5 Suppl):1364-70.

14. Grynberg M, Pierre A, Rey R, Leclerc A, Arouche N, Hesters L, et al. Differential regulation of ovarian anti-mullerian hormone (AMH) by estradiol through $\alpha$ - and $\beta$-estrogen receptors. J Clin Endocrinol Metab 2012;97:E1649-57.

15. Lee MM, Donahoe PK, Hasegawa T, Silverman B, Crist GB, Best S, et al. Mullerian inhibiting substance in humans: normal levels from infancy to adulthood. J Clin Endocrinol Metab 1996;81:5716.

16. Rajpert-De Meyts E, Jorgensen N, Graem N, Muller J, Cate RL, Skakkebaek NE. Expression of anti-Mullerian hormone during normal and pathological gonadal development: association with differentiation of Sertoli and granulosa cells. J Clin Endocrinol Metab 1999;84:3836-44.

17. Hansen KR, Knowlton NS, Thyer AC, Charleston JS, Soules MR, Klein NA. A new model of reproductive aging: the decline in ovarian non-growing follicle number from birth to menopause. Hum Reprod 2008;23:699-708.

18. de Vet A, Laven JS, de Jong FH, Themmen AP, Fauser BC. Antimullerian hormone serum levels: a putative marker for ovarian aging. Fertil Steril 2002;77:357-62.

19. Tsepelidis S, Devreker F, Demeestere I, Flahaut A, Gervy Ch, Englert $Y$. Stable serum levels of anti-Mullerian hormone during the menstrual cycle: a prospective study in normo-ovulatory women. Hum Reprod 2007;22:1837-40.

20. Hehenkamp WJ, Looman CW, Themmen AP, de Jong FH, Te Velde ER, Broekmans FJ. Anti-Mullerian hormone levels in the spontaneous menstrual cycle do not show substantial fluctuation. J Clin Endocrinol Metab 2006;91:4057-63.

21. van Disseldorp J, Lambalk CB, Kwee J, Looman CW, Eijkemans MJ, Fauser BC, et al. Comparison of inter- and intra-cycle variability of anti-Mullerian hormone and antral follicle counts. Hum Reprod 2010;25:221-7. 
22. Sherman BM, West JH, Korenman SG. The menopausal transition: analysis of $\mathrm{LH}, \mathrm{FSH}$, estradiol, and progesterone concentrations during menstrual cycles of older women. J Clin Endocrinol Metab 1976;42:629-36.

23. Fauser BC, Van Heusden AM. Manipulation of human ovarian function: physiological concepts and clinical consequences. Endocr Rev 1997;18:71-106.

24. Welt CK, McNicholl DJ, Taylor AE, Hall JE. Female reproductive aging is marked by decreased secretion of dimeric inhibin. J Clin Endocrinol Metab 1999;84:105-11.

25. Klein NA, Illingworth PJ, Groome NP, McNeilly AS, Battaglia DE, Soules MR. Decreased inhibin $B$ secretion is associated with the monotropic FSH rise in older, ovulatory women: a study of serum and follicular fluid levels of dimeric inhibin A and B in spontaneous menstrual cycles. J Clin Endocrinol Metab 1996;81:2742-5.

26. van Rooij IA, Broekmans FJ, Scheffer GJ, Looman CW, Habbema JD, de Jong $\mathrm{FH}$, et al. Serum antimullerian hormone levels best reflect the reproductive decline with age in normal women with proven fertility: a longitudinal study. Fertil Steril 2005;83:979-87.

27. Lee JY, Jee BC, Lee JR, Kim CH, Park T, Yeon BR, et al. Age-related distributions of anti-Mullerian hormone level and anti-Mullerian hormone models. Acta Obstet Gynecol Scand 2012;91:9705.

28. Lie Fong S, Visser JA, Welt CK, de Rijke YB, Eijkemans MJ, Broekmans FJ, et al. Serum anti-mullerian hormone levels in healthy females: a nomogram ranging from infancy to adulthood. J Clin Endocrinol Metab 2012;97:4650-5.

29. La Marca A, Sighinolfi G, Giulini S, Traglia M, Argento C, Sala C, et al. Normal serum concentrations of anti-Mullerian hormone in women with regular menstrual cycles. Reprod Biomed Online 2010;21:463-9.

30. Delvigne A, Rozenberg S. Epidemiology and prevention of ovarian hyperstimulation syndrome (OHSS): a review. Hum Reprod Update 2002;8:559-77.

31. Bancsi LF, Huijs AM, den Ouden CT, Broekmans FJ, Looman CW, Blankenstein MA, et al. Basal follicle-stimulating hormone levels are of limited value in predicting ongoing pregnancy rates after in vitro fertilization. Fertil Steril 2000;73:552-7.

32. Baart EB, Martini E, van den Berg I, Macklon NS, Galjaard RJ, Fauser BC, et al. Preimplantation genetic screening reveals a high incidence of aneuploidy and mosaicism in embryos from young women undergoing IVF. Hum Reprod 2006;21:223-33.

33. Luna M, Grunfeld L, Mukherjee T, Sandler B, Copperman AB. Moderately elevated levels of basal follicle-stimulating hormone in young patients predict low ovarian response, but should not be used to disqualify patients from attempting in vitro fertilization. Fertil Steril 2007;87:782-7.
34. Heijnen EM, Eijkemans MJ, De Klerk C, Polinder S, Beckers NG, Klinkert ER, et al. A mild treatment strategy for in-vitro fertilisation: a randomised non-inferiority trial. Lancet 2007;369:743-9.

35. Eldar-Geva T, Ben-Chetrit A, Spitz IM, Rabinowitz R, Markowitz E, Mimoni T, et al. Dynamic assays of inhibin B, anti-Mullerian hormone and estradiol following FSH stimulation and ovarian ultrasonography as predictors of IVF outcome. Hum Reprod 2005;20:3178-83.

36. Verberg MF, Eijkemans MJ, Macklon NS, Heijnen EM, Baart EB, Hohmann FP, et al. The clinical significance of the retrieval of a low number of oocytes following mild ovarian stimulation for IVF: a meta-analysis. Hum Reprod Update 2009;15:5-12.

37. van der Gaast MH, Eijkemans MJ, van der Net JB, de Boer EJ, Burger CW, van Leeuwen FE, et al. Optimum number of oocytes for a successful first IVF treatment cycle. Reprod Biomed Online 2006;13:476-80.

38. Erdem M, Erdem A, Gursoy R, Biberoglu K. Comparison of basal and clomiphene citrate induced FSH and inhibin B, ovarian volume and antral follicle counts as ovarian reserve tests and predictors of poor ovarian response in IVF. J Assist Reprod Genet 2004;21:37-45.

39. Broer SL, Dolleman M, van Disseldorp J, Broeze KA, Opmeer BC, Bossuyt PM, et al. Prediction of an excessive response in in vitro fertilization from patient characteristics and ovarian reserve tests and comparison in subgroups: an individual patient data meta-analysis. Fertil Steril 2013;100:420-9.

40. Kwee J, Schats R, McDonnell J, Themmen A, de Jong F, Lambalk C. Evaluation of anti-Mullerian hormone as a test for the prediction of ovarian reserve. Fertil Steril 2008;90:737-43.

41. Nelson SM, Yates RW, Fleming R. Serum anti-Mullerian hormone and FSH: prediction of live birth and extremes of response in stimulated cycles--implications for individualization of therapy. Hum Reprod 2007;22:2414-21.

42. Lee $\mathrm{TH}$, Liu CH, Huang CC, Wu YL, Shih YT, Ho HN, et al. Serum anti-Mullerian hormone and estradiol levels as predictors of ovarian hyperstimulation syndrome in assisted reproduction technology cycles. Hum Reprod 2008;23:160-7.

43. Nardo LG, Gelbaya TA, Wilkinson H, Roberts SA, Yates A, Pemberton $\mathrm{P}$, et al. Circulating basal anti-Mullerian hormone levels as predictor of ovarian response in women undergoing ovarian stimulation for in vitro fertilization. Fertil Steril 2009;92:1586-93.

44. Hendriks DJ, Mol BW, Bancsi LF, Te Velde ER, Broekmans FJ. Antral follicle count in the prediction of poor ovarian response and pregnancy after in vitro fertilization: a meta-analysis and comparison with basal follicle-stimulating hormone level. Fertil Steril 2005;83:291-301.

45. Lee JE, Lee JR, Jee BC, Suh CS, Kim KC, Lee WD, et al. Clinical ap- 
plication of anti-Mullerian hormone as a predictor of controlled ovarian hyperstimulation outcome. Clin Exp Reprod Med 2012; 39:176-81.

46. Moon KY, Kim H, Lee JY, Lee JR, Jee BC, Suh CS, et al. Nomogram to predict the number of oocytes retrieved in controlled ovarian stimulation. Clin Exp Reprod Med 2016;43:112-8.

47. La Marca A, Sighinolfi G, Radi D, Argento C, Baraldi E, Artenisio $\mathrm{AC}$, et al. Anti-Mullerian hormone (AMH) as a predictive marker in assisted reproductive technology (ART). Hum Reprod Update 2010;16:113-30.

48. van Rooij IA, Tonkelaar Id, Broekmans FJ, Looman CW, Scheffer $\mathrm{GJ}$, de Jong FH, et al. Anti-mullerian hormone is a promising predictor for the occurrence of the menopausal transition. Menopause 2004;11(6 Pt 1):601-6.

49. Ficicioglu C, Kutlu T, Baglam E, Bakacak Z. Early follicular antimullerian hormone as an indicator of ovarian reserve. Fertil Steril 2006;85:592-6.

50. van Rooij IA, Broekmans FJ, te Velde ER, Fauser BC, Bancsi LF, de Jong $\mathrm{FH}$, et al. Serum anti-Mullerian hormone levels: a novel measure of ovarian reserve. Hum Reprod 2002;17:3065-71.

51. Broer SL, Eijkemans MJ, Scheffer GJ, van Rooij IA, de Vet A, Themmen AP, et al. Anti-mullerian hormone predicts menopause: a long-term follow-up study in normoovulatory women. J Clin Endocrinol Metab 2011;96:2532-9.

52. Bertone-Johnson ER, Manson JE, Purdue-Smithe AC, Steiner AZ, Eliassen AH, Hankinson SE, et al. Anti-Mullerian hormone levels and incidence of early natural menopause in a prospective study. Hum Reprod 2018;33:1175-82.

53. Depmann M, Eijkemans MJ, Broer SL, Tehrani FR, SolaymaniDodaran M, Azizi F, et al. Does AMH relate to timing of menopause? Results of an individual patient data meta- analysis. J Clin Endocrinol Metab 2018;103:3593-600.

54. Schuh-Huerta SM, Johnson NA, Rosen MP, Sternfeld B, Cedars $\mathrm{MI}$, Reijo Pera RA. Genetic variants and environmental factors associated with hormonal markers of ovarian reserve in Caucasian and African American women. Hum Reprod 2012;27:594608.

55. Bhide P, Gudi A, Shah A, Homburg R. Serum anti-Mullerian hormone levels across different ethnic groups: a cross-sectional study. BJOG 2015;122:1625-9.

56. Tal R, Seifer DB. Potential mechanisms for racial and ethnic differences in antimullerian hormone and ovarian reserve. Int J Endocrinol 2013;2013:818912.

57. Gleicher N, Weghofer A, Oktay K, Barad DH. Correlation of triple repeats on the FMR1 (fragile $X$ ) gene to ovarian reserve: a new infertility test? Acta Obstet Gynecol Scand 2009;88:1024-30.

58. Laven JS, Mulders AG, Visser JA, Themmen AP, De Jong FH,
Fauser BC. Anti-Mullerian hormone serum concentrations in normoovulatory and anovulatory women of reproductive age. J Clin Endocrinol Metab 2004;89:318-23.

59. Pigny P, Merlen E, Robert Y, Cortet-Rudelli C, Decanter C, Jonard $\mathrm{S}$, et al. Elevated serum level of anti-mullerian hormone in patients with polycystic ovary syndrome: relationship to the ovarian follicle excess and to the follicular arrest. J Clin Endocrinol Metab 2003;88:5957-62.

60. Pellatt L, Hanna L, Brincat M, Galea R, Brain H, Whitehead S, et al. Granulosa cell production of anti-Mullerian hormone is increased in polycystic ovaries. J Clin Endocrinol Metab 2007;92:240-5.

61. Dewailly D, Catteau-Jonard S, Reyss AC, Maunoury-Lefebvre C, Poncelet E, Pigny P. The excess in 2-5 mm follicles seen at ovarian ultrasonography is tightly associated to the follicular arrest of the polycystic ovary syndrome. Hum Reprod 2007;22:15626.

62. Tal R, Seifer DB, Khanimov M, Malter HE, Grazi RV, Leader B. Characterization of women with elevated antimullerian hormone levels (AMH): correlation of AMH with polycystic ovarian syndrome phenotypes and assisted reproductive technology outcomes. Am J Obstet Gynecol 2014;211:59.e1-8.

63. Pierre A, Peigne M, Grynberg M, Arouche N, Taieb J, Hesters L, et al. Loss of LH-induced down-regulation of anti-Mullerian hormone receptor expression may contribute to anovulation in women with polycystic ovary syndrome. Hum Reprod 2013; 28:762-9.

64. Vendola KA, Zhou J, Adesanya OO, Weil SJ, Bondy CA. Androgens stimulate early stages of follicular growth in the primate ovary. J Clin Invest 1998;101:2622-9.

65. Weil S, Vendola K, Zhou J, Bondy CA. Androgen and folliclestimulating hormone interactions in primate ovarian follicle development. J Clin Endocrinol Metab 1999;84:2951-6.

66. Nardo LG, Yates AP, Roberts SA, Pemberton P, Laing I. The relationships between $A M H$, androgens, insulin resistance and basal ovarian follicular status in non-obese subfertile women with and without polycystic ovary syndrome. Hum Reprod 2009;24: 2917-23.

67. Park HT, Cho GJ, Ahn KH, Shin JH, Kim YT, Hur JY, et al. Association of insulin resistance with anti-Mullerian hormone levels in women without polycystic ovary syndrome (PCOS). Clin Endocrinol (Oxf) 2010;72:26-31.

68. Jadoul P, Kitajima M, Donnez O, Squifflet J, Donnez J. Surgical treatment of ovarian endometriomas: state of the art? Fertil Steril 2012;98:556-63.

69. Hachisuga T, Kawarabayashi T. Histopathological analysis of laparoscopically treated ovarian endometriotic cysts with spe- 
cial reference to loss of follicles. Hum Reprod 2002;17:432-5.

70. Muzii L, Bellati F, Bianchi A, Palaia I, Manci N, Zullo MA, et al. Laparoscopic stripping of endometriomas: a randomized trial on different surgical techniques. Part II: pathological results. Hum Reprod 2005;20:1987-92.

71. Roman H, Tarta O, Pura I, Opris I, Bourdel N, Marpeau L, et al. Direct proportional relationship between endometrioma size and ovarian parenchyma inadvertently removed during cystectomy, and its implication on the management of enlarged endometriomas. Hum Reprod 2010;25:1428-32.

72. Busacca M, Vignali M. Endometrioma excision and ovarian reserve: a dangerous relation. J Minim Invasive Gynecol 2009; 16:142-8.

73. Alborzi S, Keramati P, Younesi M, Samsami A, Dadras N. The impact of laparoscopic cystectomy on ovarian reserve in patients with unilateral and bilateral endometriomas. Fertil Steril 2014; 101:427-34.

74. Chang HJ, Han SH, Lee JR, Jee BC, Lee BI, Suh CS, et al. Impact of laparoscopic cystectomy on ovarian reserve: serial changes of serum anti-Mullerian hormone levels. Fertil Steril 2010;94:3439.

75. Goodman LR, Goldberg JM, Flyckt RL, Gupta M, Harwalker J, Falcone T. Effect of surgery on ovarian reserve in women with endometriomas, endometriosis and controls. Am J Obstet Gynecol 2016;215:589.

76. Uncu G, Kasapoglu I, Ozerkan K, Seyhan A, Oral Yilmaztepe A, Ata $B$. Prospective assessment of the impact of endometriomas and their removal on ovarian reserve and determinants of the rate of decline in ovarian reserve. Hum Reprod 2013;28:2140-5.

77. Kwon SK, Kim SH, Yun SC, Kim DY, Chae HD, Kim CH, et al. Decline of serum antimullerian hormone levels after laparoscopic ovarian cystectomy in endometrioma and other benign cysts: a prospective cohort study. Fertil Steril 2014;101:435-41.

78. Anderson RA, Rosendahl M, Kelsey TW, Cameron DA. Pretreatment anti-Mullerian hormone predicts for loss of ovarian function after chemotherapy for early breast cancer. Eur J Cancer 2013;49:3404-11.

79. Lee DY, Park YH, Lee JE, Choi D. Prediction of ovarian function recovery in young breast cancer patients after protection with gonadotropin-releasing hormone agonist during chemotherapy. Breast Cancer Res Treat 2018;171:649-56.

80. Kim HA, Choi J, Park CS, Seong MK, Hong SE, Kim JS, et al. Postchemotherapy serum anti-Mullerian hormone level predicts ovarian function recovery. Endocr Connect 2018;7:949-56.

81. van den Berg MH, van Dulmen-den Broeder E, Overbeek A, Twisk JW, Schats R, van Leeuwen FE, et al. Comparison of ovarian function markers in users of hormonal contraceptives during the hormone-free interval and subsequent natural early follicular phases. Hum Reprod 2010;25:1520-7.

82. Bentzen JG, Forman JL, Pinborg A, Lidegaard O, Larsen EC, FriisHansen $L$, et al. Ovarian reserve parameters: a comparison between users and non-users of hormonal contraception. Reprod Biomed Online 2012;25:612-9.

83. Dewailly D, Andersen CY, Balen A, Broekmans F, Dilaver N, Fanchin $\mathrm{R}$, et al. The physiology and clinical utility of anti-Mullerian hormone in women. Hum Reprod Update 2014;20:370-85.

84. Birch Petersen K, Hvidman HW, Forman JL, Pinborg A, Larsen EC, Macklon KT, et al. Ovarian reserve assessment in users of oral contraception seeking fertility advice on their reproductive lifespan. Hum Reprod 2015;30:2364-75.

85. van Heusden AM, Coelingh Bennink HJ, Fauser BC. FSH and ovarian response: spontaneous recovery of pituitary-ovarian activity during the pill-free period vs. exogenous recombinant FSH during high-dose combined oral contraceptives. Clin Endocrinol (Oxf) 2002;56:509-17.

86. Jungheim ES, Travieso JL, Carson KR, Moley KH. Obesity and reproductive function. Obstet Gynecol Clin North Am 2012;39: 479-93.

87. Freeman EW, Gracia CR, Sammel MD, Lin H, Lim LC, Strauss JF 3rd. Association of anti-mullerian hormone levels with obesity in late reproductive-age women. Fertil Steril 2007;87:101-6.

88. Buyuk E, Seifer DB, Illions E, Grazi RV, Lieman H. Elevated body mass index is associated with lower serum anti-mullerian hormone levels in infertile women with diminished ovarian reserve but not with normal ovarian reserve. Fertil Steril 2011;95:23648.

89. Moslehi N, Shab-Bidar S, Ramezani Tehrani F, Mirmiran P, Azizi F. Is ovarian reserve associated with body mass index and obesity in reproductive aged women? A meta-analysis. Menopause 2018;25:1046-55.

90. Chodosh LA. Expression of BRCA1 and BRCA2 in normal and neoplastic cells. J Mammary Gland Biol Neoplasia 1998;3:389402.

91. Oktay K, Kim JY, Barad D, Babayev SN. Association of BRCA1 mutations with occult primary ovarian insufficiency: a possible explanation for the link between infertility and breast/ovarian cancer risks. J Clin Oncol 2010;28:240-4.

92. Wang ET, Pisarska MD, Bresee C, Chen YD, Lester J, Afshar Y, et al. BRCA1 germline mutations may be associated with reduced ovarian reserve. Fertil Steril 2014;102:1723-8.

93. Johnson L, Sammel MD, Domchek S, Schanne A, Prewitt M, Gracia C. Antimullerian hormone levels are lower in BRCA2 mutation carriers. Fertil Steril 2017;107:1256-65.

94. Michaelson-Cohen R, Mor P, Srebnik N, Beller U, Levy-Lahad E, 
Eldar-Geva T. BRCA mutation carriers do not have compromised ovarian reserve. Int J Gynecol Cancer 2014;24:233-7.

95. Merhi Z, Doswell A, Krebs K, Cipolla M. Vitamin D alters genes involved in follicular development and steroidogenesis in human cumulus granulosa cells. J Clin Endocrinol Metab 2014;99: E1137-45.

96. Dennis NA, Houghton LA, Jones GT, van Rij AM, Morgan K, McLennan IS. The level of serum anti-Mullerian hormone correlates with vitamin D status in men and women but not in boys. J Clin Endocrinol Metab 2012;97:2450-5.

97. Pearce K, Gleeson K, Tremellen K. Serum anti-Mullerian hormone production is not correlated with seasonal fluctuations of vitamin D status in ovulatory or PCOS women. Hum Reprod 2015;30:2171-7.

98. Drakopoulos P, van de Vijver A, Schutyser V, Milatovic S, Anckaert $E$, Schiettecatte J, et al. The effect of serum vitamin $D$ levels on ovarian reserve markers: a prospective cross-sectional study. Hum Reprod 2017;32:208-14.

99. Jeppesen JV, Anderson RA, Kelsey TW, Christiansen SL, Kristensen SG, Jayaprakasan K, et al. Which follicles make the most anti-Mullerian hormone in humans? Evidence for an abrupt decline in AMH production at the time of follicle selection. Mol Hum Reprod 2013;19:519-27.

100. Dewailly D, Gronier H, Poncelet E, Robin G, Leroy M, Pigny P, et al. Diagnosis of polycystic ovary syndrome (PCOS): revisiting the threshold values of follicle count on ultrasound and of the serum AMH level for the definition of polycystic ovaries. Hum Reprod 2011;26:3123-9.

101. Victoria M, Labrosse J, Krief F, Cedrin-Durnerin I, Comtet M, Grynberg M. Anti Mullerian hormone: more than a biomarker of female reproductive function. J Gynecol Obstet Hum Reprod 2019;48:19-24.

102. Teede HJ, Misso ML, Costello MF, Dokras A, Laven J, Moran L, et al. Recommendations from the international evidence-based guideline for the assessment and management of polycystic ovary syndrome. Hum Reprod 2018;33:1602-18.

103. Dumont A, Robin G, Catteau-Jonard S, Dewailly D. Role of antiMullerian hormone in pathophysiology, diagnosis and treatment of polycystic ovary syndrome: a review. Reprod Biol Endocrinol 2015;13:137.

104. Steiner AZ, Pritchard D, Stanczyk FZ, Kesner JS, Meadows JW, Herring $\mathrm{AH}$, et al. Association between biomarkers of ovarian reserve and infertility among older women of reproductive age. JAMA 2017;318:1367-76.

105. Koo HS, Song IO, Cha SH, Park CW, Kim HO. The likelihood of achieving pregnancy through timed coitus in young infertile women with decreased ovarian reserve. Clin Exp Reprod Med 2018;45:31-7. 